\title{
Projection of the hydraulic pressure drive with application of partial synthesis
}

\author{
Alexander T. Rybak*, Alexey Yu. Pelipenko, Mikhail P. Shishkarev, and \\ Marina Yu. Nevzorova \\ Don State Technical University, 344000 Rostov-on-Don, Russian Federation
}

\begin{abstract}
In this article "Projection of a Hydraulic Pressure Drive with Application of Partial Synthesis" for the best comprehension and also receiving more complete picture, definitions of the term projection are considered, some fields of activity in which it is applied, namely technological, agricultural mechanical engineering etc are listed. An important part of cars, the drive is, the hydraulic actuator is most often applied - projection of which will be described in this article. First of all the existing technique projection of a hydraulic actuator is considered and its principle is described and shortcomings are designated.For carrying out a better designing process the new technique of projection of a hydraulic pressure drive which includes a stage of partial synthesis is offered. This stage allows explaining the theory of a volume rigidity which in turn allows to simplify calculations because it is possible to count several options of preliminary structures at the same time that will lead to receiving a hydraulic actuator with the best parameters, unlike the previous considered technique.
\end{abstract}

\section{Introduction}

Projection - the integral stage of life cycle for the created object/product, without projection it is impossible to create it according to the stated characteristics.

There are a lot of projection definitions, for more complete comprehension of the term and its essence we will consider some of them.

For example, J. K. Jones offers more than projection ten definitions from which main thing, according to his mind: "projection - the kind of activity giving rise for changes in an artificial atmosphere". [1]

V.S. Kuznetsov defines the design process as the main component, creating new concepts and concepts. [2]

The purpose of projection is development and obtaining of the solution of given objectives, documentation necessary for creation and production of a designed project. Result of projection is the set (technical) project documentation by means of which, further the conceived projectwill be realized.

Projection is applied in various fields of activity, for example in technological mechanical engineering, agricultural mechanical engineering etc. The most important part of processing equipment or mobile cars is the drive, it can be different types, but most often a hydraulic

*Corresponding author: 2130373@mail.ru 
pressure driveis applied.Respectively projection of a hydraulic actuator one of the most important design stages of the car or inventory, it is also necessary to pay special attention toit.

Projection of a hydraulic actuator.The projection technique of a hydraulic actuator consists of follow-up stages of the structure presented in the figure 1 [3], and also obtaining of particular results, following the realization results of each of them.

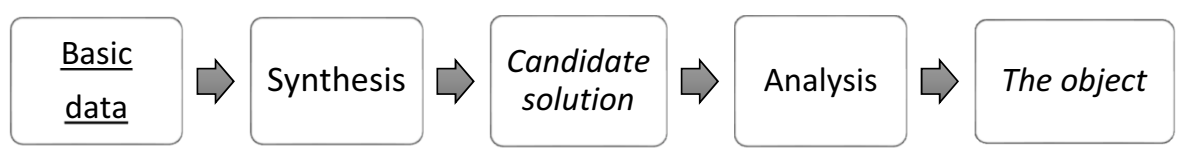

Fig. 1.The projection technique of a hydraulic actuator.

Everything begins with a research, detailed consideration and judgment of input datas, the most competent and complete formulation of necessary parameters and requirements to a designed project - this stage is the first and obligatory.

After that the stage of synthesis follows which in turn consists of structural and parametrical synthesis.In the process of structural synthesis, variants of the object representing are showing a graphical way (schemes, sketches, algorithms and other graphical representations), andin the process of parametrical synthesis the numerical decision of a design task is passed, parameters and drawings of the drive are calculated, the complete technical documentation is created.The results of the synthesis stage are the obtaining of a solution to the problem.

The following stage is "analysis". The analysis consists of a research of the received task for candidate solution, and obtaining information about its properties.

As a result of projection of a hydraulic actuator, according to this technique, the designer receives the unique candidate solution of a task, this option can correspond to necessary characteristics not completely.

Projection of a hydraulic actuator with application of partial synthesis. For carrying out of the most qualitative designing process, the projection technique represented in fig. 2 is offered. On the submitted scheme it is visible that the technique includes the padding stage "partial synthesis".

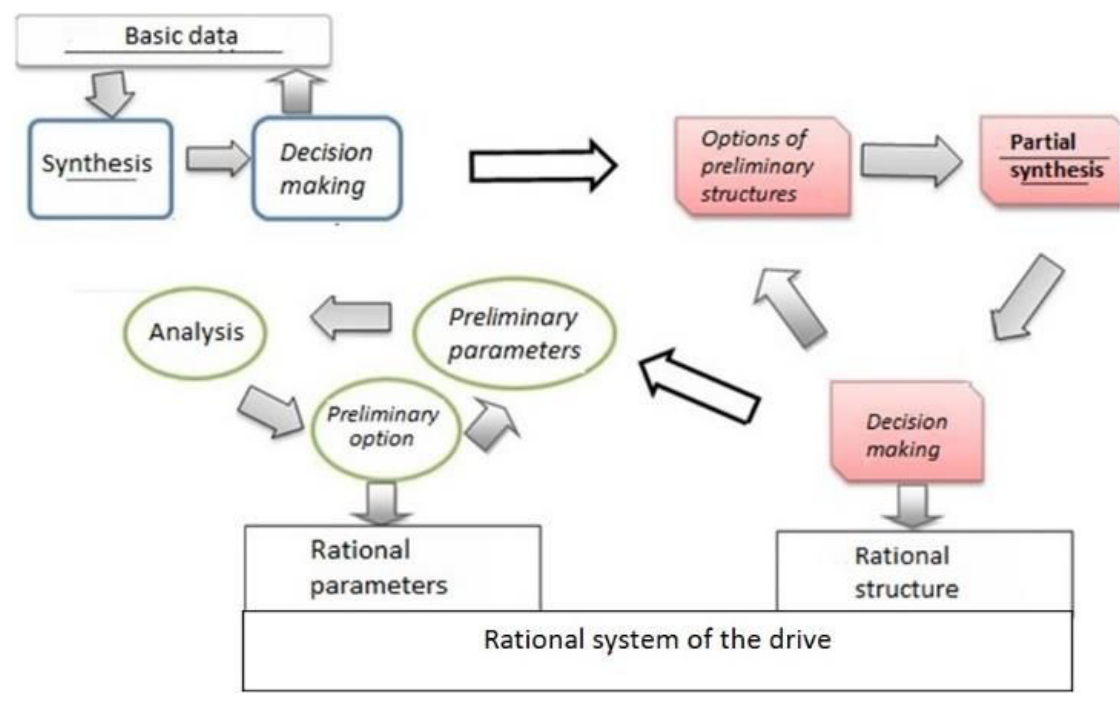

Fig. 2. The projection technique of a hydraulic pressure drive. 
Partial synthesis is carried out on the base using of the theory of a volume rigidity $[4,5]$. According to the theory of a volume rigidity pressure in any point of a hydraulic system can be determined by expression

$$
d p_{i}=C_{p r i} \cdot\left(\sum Q_{v h_{i}}-\sum Q_{v y h i}\right) \cdot d t
$$

when $\sum Q_{v h_{i}}$ and $\sum Q_{v y h i^{-}}$the sums of all entering and leaving instantaneous expenses of a hydraulic medium of the considered hydraulic system volume during $\mathrm{dt} ; C_{p r i}$ the provided coefficient of a volume rigidity of the considered $i$ volume of a hydraulic system.

For simplification of the mathematical description of the composite hydraulic system we can consider that if in some point of system several hydraulic elements are included, and each of the listed elements possesses the coefficient of a volume rigidity, the provided coefficient of a volume rigidity of such system of elements can be determined by this formula

$$
C_{p r}=\frac{\prod_{i=1}^{n} c_{i}}{\sum_{i=1}^{n}\left(\frac{1}{C_{i}} \prod_{i=1}^{n} C_{i}\right)},
$$

When $C_{p r}$ - the provided coefficient of a volume rigidity of a hydraulic system which consists of $n$ in unison of the working elements; $C_{l}$ - the provided coefficient of a volume rigidity of $i$ a system element.

There is some complexity in determination of the provided coefficients of a volume rigidity at sleeves of high pressure. As their resilient properties cannot be given into the simple analytical description, they should be defined experimentally $[6,7]$.

Thus application of the theory of a volume rigidity in projecting calculations allows to simplify and accelerate the process of calculation of system dynamic properties $[8,9]$.Now perhaps carrying out calculations of several options of preliminary structures is simultaneous. It will allow to reveal a hydraulic actuator with the best indexes, in difference from earlier considered technique

In the offered technique at the first stage basicdates are synthesizedand the decision making follows further.The procedureis repeated several times, applying different indicators.As a result from a set of optional versions of the solution inprojection goals, some quantity of options of preliminary structures are chosen (as a rule, 3-5 circuitry decisions). On the following stage under the name partial synthesis the most suitable candidate solution of an objectiveis sampled.The stage purpose is obtaining of rational structure.Further an analysis stage of preliminary parameters following the results of which the option with the best, rational parameters is chosen.

The generalized structure of projection and calculation of a hydraulic actuator takes the form presented in the figure 3.

On the offered scheme, design stages are projection. The design assignment passes a synthesis stage. Results of synthesis are options of preliminary structures. Further the procedure of partial synthesis follows. At this stage options of preliminary structures are miscalculated, basic (limitative) data for calculation are considered and the equation of coefficient of the given volume rigidity is applied. Following the results of partial synthesis the function chart (rational structure), and values of design and functional data turns out. The received preliminary parameters undergo the procedure of the analysis. Rational parameters are result of the analysis. Results of the generalized structure of projection is the final decision, namely rational structure of projection with rational parameters (the rational system of the drive). 


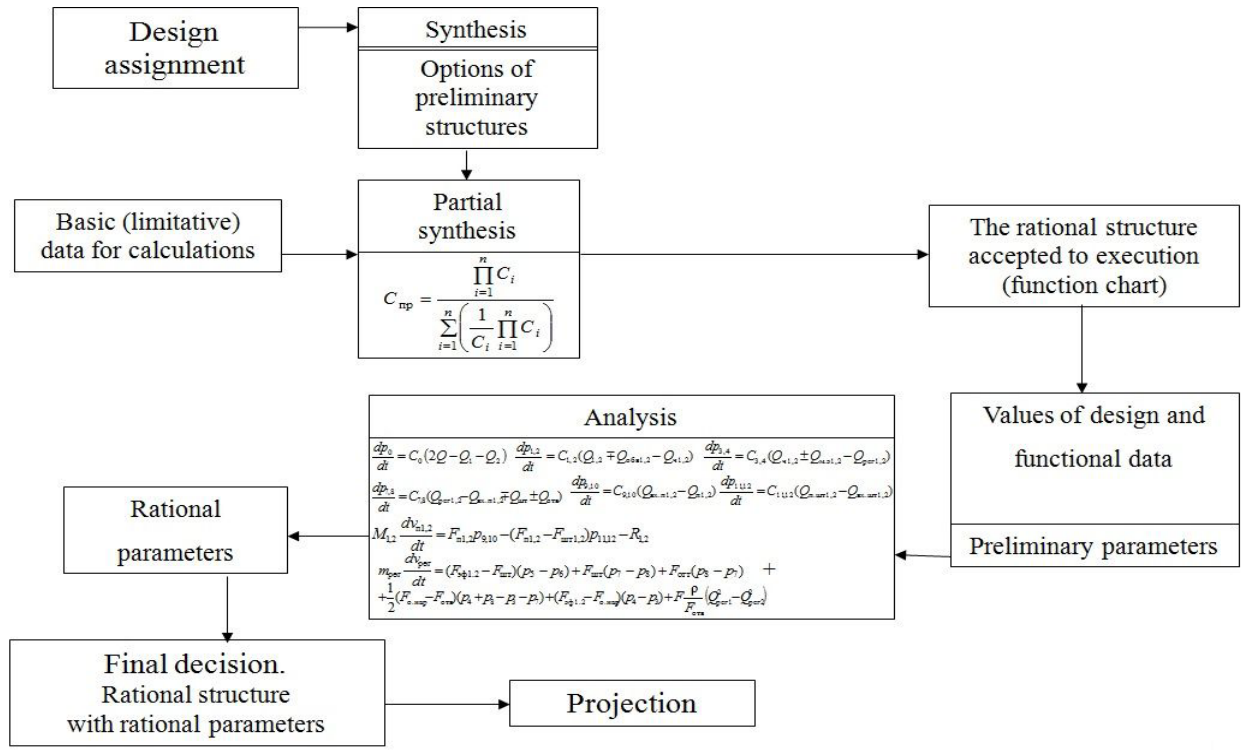

Fig. 3. The generalized structure of through projection and calculation of a hydraulic actuator.

The expected results for each stage of the offered technique of projection are presented in table 1.

Table 1. Common technique of projection of hydraulic actuators

\begin{tabular}{|c|c|c|c|c|}
\hline Stage & $\begin{array}{c}\text { I stage - } \\
\text { conceptual } \\
\text { design stage of } \\
\text { the drive } \\
\text { SYNTHESIS }\end{array}$ & $\begin{array}{l}\text { II stage - the } \\
\text { express the } \\
\text { analysis of the } \\
\text { decisions received } \\
\text { after } 1 \text { stage } \\
\text { PARTIAL } \\
\text { SYNTHESIS }\end{array}$ & $\begin{array}{l}\text { III stage - theoretical } \\
\text { researches and } \\
\text { calculations of } \\
\text { optimum parameters } \\
\text { of system of the drive } \\
\text { received as a result } \\
\text { the analysis express } \\
\text { ANALYSIS }\end{array}$ & $\begin{array}{c}\text { IV stage - } \\
\text { development of } \\
\text { technical } \\
\text { documentation }\end{array}$ \\
\hline Features & $\begin{array}{c}\text { Use in the } \\
\text { analysis mainly } \\
\text { quality design } \\
\text { indicators }\end{array}$ & $\begin{array}{l}\text { Use in the } \\
\text { analysis the } \\
\text { mainly } \\
\text { quantitative of } \\
\text { design indexes }\end{array}$ & $\begin{array}{l}\text { Use in the analysis } \\
\text { mainly the } \\
\text { quantitative design } \\
\text { indices intensive use } \\
\text { of computer facilities } \\
\text { and optimizing } \\
\text { programs }\end{array}$ & $\begin{array}{l}\text { The constructing } \\
\text { stage directed to } \\
\text { development of } \\
\text { the design } \\
\text { solution of system } \\
\text { of the drive } \\
\text { fullestly } \\
\text { corresponding to } \\
\text { results of the III } \\
\text { stage }\end{array}$ \\
\hline $\begin{array}{c}\text { The } \\
\text { achieved } \\
\text { objectives }\end{array}$ & $\begin{array}{l}\text { The restricted } \\
\text { number of the } \\
\text { most perspective } \\
\text { circuitry } \\
\text { decisions }-3-7 \\
\text { gets out of the } \\
\text { infinite set of } \\
\text { optional versions } \\
\text { of achievement } \\
\text { of the goal of } \\
\text { projection }\end{array}$ & $\begin{array}{l}\text { The choice from } \\
\text { the circuitry } \\
\text { solutions of one } \\
\text { which are fullestly } \\
\text { satisfying the } \\
\text { projection } \\
\text { purposes received } \\
\text { at the previous } \\
\text { stage }\end{array}$ & $\begin{array}{l}\text { Receiving system of } \\
\text { the drive with the best } \\
\text { operational indexes }\end{array}$ & $\begin{array}{c}\text { Receiving set of } \\
\text { design } \\
\text { documentation }\end{array}$ \\
\hline
\end{tabular}


Applying this structure of projection for a hydraulic actuator, mistakes, marriage, discrepancy of principal specifications are minimized.

\section{Conclusions}

The projection of a hydraulic pressure drive is one of the most important development stages of the drive. At this stage its principal specifications, properties are formed. In a designing process it is still possible to correct the found errors without larger material inputs and losses of resources, it is also very responsible.

It is difficult to assume what losses of time and tools will be incurred by the production in work, for example of farm vehicles which hydraulic actuator has marriage and discrepancy to the stated characteristics.

\section{References}

1. Ertas, A., Jones, J. C., The Engineering Design Process (John Wiley and Sons, New York, 1996)

2. Y. V. Kuznetsov, E. V. Melaykova, Teoriaorganizaciy: ychebnik dlay bakalavrov (YuRait, Moscow, 2015)

3. A.T. Rybak, I.V. Boguslavskiy, Vestnik of the DSTU, 276 (2010)

4. A.T. Rybak, Gidromekhanicheskie sistemy. Modelirovanie $i$ raschet: monograph (Gos. Tekh. Univ., Rostov-on-Don: Donetsk, 2008)

5. A.T. Rybak, Teorija $i$ metodologija raschjota $i$ proektirovanija system privodov tehnologicheskih mashin i agregatov, APK. Dokt. Diss. (Rostov-on-Don, 2011)

6. A.T.Rybak, V.P. Zharov, V.I. Mirnyj, S.A. Zatolokin, Proc. DTS-2007, 66 (2007)

7. A.Rybak, O. Lyakhnitskaya, MATEC WebConf, 132, 01001(2017)

8. A.T. Rybak, V.P. Zharov, A.V. Serdyukov, Russian Engineering Research, 28 (2), 194(2009)

9. A. T. Rybak, A. R. Temirkanov, O. V. Lyakhnitskaya, Russian Engineering Research. 38(3), 212 (2018) 